\title{
Water Hummer Technology for Soil Destruction on Dredgers
}

\author{
Igor Z. Maslov, Valentin I. Chimshir, Varvara M. Piterska, Anzhela I. Haidarzhy
}

\begin{abstract}
The present investigation aims to propose a solution of the problem which is connected with slurry processing during the dredger's operation under difficult conditions. On dredgers, depending on the degree of air dryness or low ambient temperatures very often arises technical problem that creates difficulties for the crew. It is connected with the fact that soil surface layer is very dense. It is very difficult to dredge the soil during extraction under water surface or unloading from the hold of a vessel at low ambient temperatures. The top layer of the very soil is characterized by a high degree of compaction and can be destroyed in two ways only. The first way is to use very powerful mechanical equipment (percussion mechanisms, vibration equipment, etc.). This method is associated with high energy spending and its use on a vessel is technically difficult. The second way is to use the soil cutting process with the use of mechanical cutters. Dredger's operation with the use of milling equipment is always characterized by the fact that during soil mechanical treatment there is always occurs breakage of the cutter teeth or rapid wear of the cutting surfaces. A similar problem occurs when sandy or clay soil is extracted under water, which is compacted by its properties. In investigation a non-trivial solution was used to solve the problem of destruction of the compacted soil layer during the operation of the dredger. It was proposed to use the hydrodynamic method based on water hammer as the main mechanism for the destruction of compacted soil. As a result of the interaction of the compacted soil layer and high pressurized directed water jets, good performance of the dredger can be achieved. The two-dimensional mechanism of destruction of the compacted soil layer can be described by the condition of dynamic equilibrium of the three main flows - the jet, which flows from the conical nozzle and two flows along the soil surface. For these streams, a reactive force evaluation has been performed. Destructive jets can be generated by standard marine pumps in combination with the use of water hammer. Based on the results of the experiments, it was found that the qualitative destruction of the surface layer of compacted soil occurs using two or three phases of hydraulic water hummer.
\end{abstract}

Keywords : dredger, compacted soil, surface layer destruction technology, high pressure jet, water hammer.

Revised Manuscript Received on February 05, 2020.

* Correspondence Author

Igor Z. Maslov, Associate Professor, Department of Power Plants Operation and Systems, Danube Institute of the National University "Odesa Maritime Academy", Izmail City, Ukraine.

Valentin I. Chimshir, Associate Professor, Danube Institute of the National University “Odesa Maritime Academy", Izmail City, Ukraine.

Varvara M. Piterska, Professor, Department of Port Operations and Cargo Works Technology, Odessa National Maritime University, Odessa Ukraine

Anzhela I. Haidarzhy, Senior Lecturer, Department of Navigation and Ship Management Academic Services, Danube Institute of the National University “Odesa Maritime Academy".

(C) The Authors. Published by Blue Eyes Intelligence Engineering and Sciences Publication (BEIESP). This is an open access article under the CC BY-NC-ND license (http://creativecommons.org/licenses/by-nc-nd/4.0/)

\section{INTRODUCTION}

In the world, the extraction of soil under the water surface and its transportation over long distances is carried out by dredgers only [1]. Modernization of technologies, which are used for soil extraction, processing or unloading, if used correctly, can lead to a significant increase in income during the operation of the dredger and will lead to a decrease in the downtime of the vessel at the place of slurry extraction or storage [2]. As the main result of such a modernization of the technological scheme of the vessel's operation, it is possible to single out the possibility of unloading the entire transported soil without ballast residues in cargo holds. It can be stated that on the dredgers at the present time there are almost absent technical units and technologies that allow to destroy compacted soil directly during unloading of holds. In other words, the development of new systems or equipment that can reduce the time of destruction of the compacted soil layer is very actual and perspective from the point of view of dredger's operation.

All methods used for industrial destruction of a compacted surface layer of a soil surface are mechanical. They all are characterizing by high energy costs. Depending on the method, which is used to apply a mechanical load onto the soil, these technologies can be subdivided as: vibrational, vibration-shock, impact and milling.

In the case when the destruction of the surface soil layer, which has become dense due to icing, is carried out, any kind of mechanical load should be applied locally. It must be focused on a specific section of the trench or fracture area. For this reason, all the working parts of the mechanisms that are used to destroy the compacted soil layer are equipped with mechanical destroyers - teeth, cutting knives, milling cutters, etc. [3]. These destroyers are characterized by two distinctive features - a small area of contact with the soil and the possibility of creating high pressure in locally distinguished areas.

Most qualitatively, and with the lowest energy costs, the process of soil destruction can occur when the speed of the action of the actuating element exceeds or is comparable to the expansion speed of plastic deformations inside the soil.

After analysis of all designs of marine mechanical soil destructors, it can be stated that these devices have low performance values. Mainly it caused by very low cutting speed of the soil trench and the strong dependence of the technology on the shape of the cutter, the geometry of the impact wedges, as well as the material and type of cutting surface. 


\section{Water Hummer Technology for Soil Destruction on Dredgers}

\section{PROBLEM STATEMENT}

From a technical point of view, one of the most suitable devices for loosening the soil can be a technique that uses high-pressure jets. According to [4], a jet is a type of motion of liquid or gas that limited by the surface of a tangential discontinuity. On this surface, takes place discontinuity of the flow characteristics such as velocity, temperature, impurity concentration, etc. Due to such a tangential discontinuity, a transverse transfer of momentum from the jet to its surrounding space occurs [5]. One of the sources of high-pressure jets can be water hummer - a directed shock wave with high pressure.

When considering hydraulic erosion, the physical mechanism of the impact interaction of the water jet with the surface of the developed soil is of particular importance. Depending on the degree of compaction of the surface layer, the mechanism of soil destruction can vary significantly. In accordance with [6], dense and porous soil are destroyed differently. A more porous soil always experiences less powerful impact loads.

When setting the state equation of the medium and the relationship of internal energy with parameters that determine the state of material, it is possible to create the Hugoniot adiabat, which connects the shock pressure with the density of the substance. In general, such a relationship has the form

$$
P=\frac{\rho_{0} C_{a}^{2}}{n} \frac{\left(h-\frac{n+1}{n-1}\right)+\sigma \frac{2 n}{n-1}-(h+1)}{h-K \sigma}
$$

where $P$ - shock pressure, $\mathrm{Pa} ; \rho_{0}, \rho$ - density of a mass unit of the working substance in front of and behind the shock pressure wave, $\mathrm{kg} / \mathrm{m}^{3} ; C_{a}$ - coefficient describing the internal structure of the substance (for porous soils $\mathrm{Ca}=1000-2300$ $\mathrm{m} / \mathrm{s}$ ); $\sigma=\frac{\rho}{\rho_{0}}-$ value of compression (for water $\sigma=1$ ); $h-$ index of polytropy; $K$ - factor of the substance porosity.

In case, when environmental air is characterized by increased humidity or low temperature, the porous or fine soil during transportation in the hold of the vessel will be compacted. It happens because of the processes of adhesion, surface drainage, or due to glaciation of moisture at low transportation temperatures. The combination of these processes usually leads to compaction of the entire mass of soil and the inevitable difficulties in its subsequent unloading. In some cases (usually at low temperatures) the appearance of a surface compacted layer creates many problems for the operation of cargo unloading from the hold of a vessel or even makes this operation impossible.

One of the solutions to this problem can be the use of the process of local destruction of the surface soil layer by force of contact-mechanical action. The use of water hammer can be the most effective and simplest solution to such a problem [7]. Due to the use of high pressure of the shock jet and its small size, it is possible to obtain local destruction of the soil in almost any of its areas. In the operations of unloading cargo from the hold of a vessel, the addition of water to the soil during the hydraulic erosion operation will also have a positive effect. In this technology, there will be an increase in the discharge characteristics of the soil pipeline during the movement of slurry inside it [8].

The problem solution for destruction of the compacted soil layer when it is extracted under the water level or when unloading from the holds of a vessel is directly connected with the creation of a new technology for the hydraulic soil destruction system. Most of the problems related to the interaction of a liquid stream and a dense layer of soil during a water hammer remain unexplored. For this reason, the main research problem should be related to the development of a universal technical system for the destruction of the compacted soil layer, taking into account new data on the effect of hydraulic shock parameters on the nature of such destruction.

\section{METHODOLOGY}

New ship technological scheme for study the degree of influence of water hammer parameters onto the process of soil destruction was developed. It is shown in Figure 1 and present itself a mechanical connection of pipelines that contain sets of holes along their length. To create high pressure jets, a conical nozzle was additionally installed on each hole. The connection of all sections was carried out on the principle of a complex annular pipeline [9], [10].

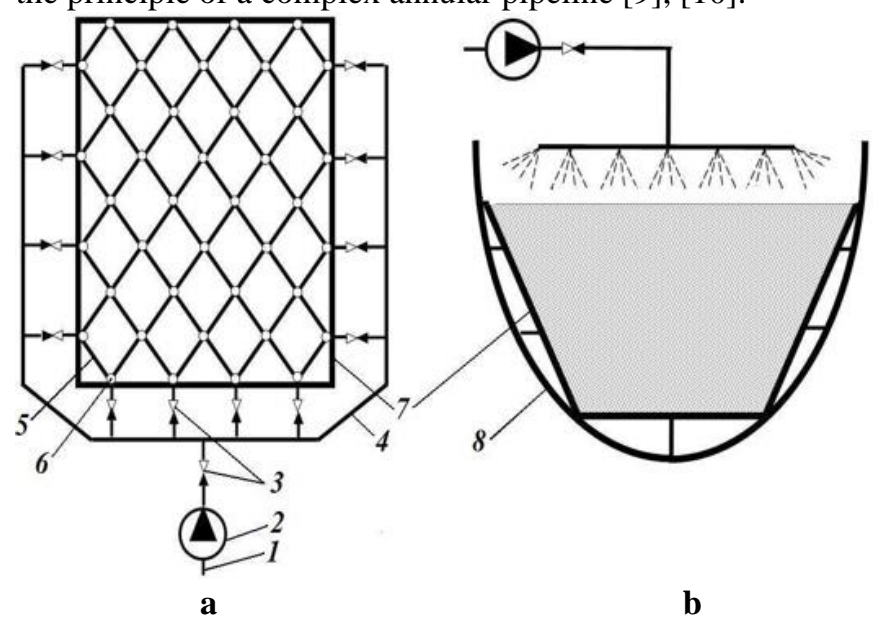

Fig. 1 Ship technological scheme

a - top view; $b$ - side view

1 - main pipeline; 2 - pump; 3 - electromagnetic valve; 4 contour pipeline

The technological scheme for investigating the process of soil destruction due to high-pressure jets during a water hammer generally works as follows: for the destruction of the compacted soil layer through the main pipeline 1 , water is supplied by pump 2 . The water is not supplied continuously, but cyclically. For quick water turn off, an automatically controlled solenoid valve 3 is installed behind the pump. This valve simultaneously performs the main function during the operation of the system - due to its short-term closure, valve 3 creates shock waves in the system of circuit 4 and operating pipelines 5. Partial flow rates supplied directly to the erosion line 5 from the contour pipeline 4 are controlled by the operation of the valve system. These valves are installed on each input line into a closed annular hydraulic circuit. Due to the hydraulic shock waves created in the system, water, through conical nozzles 6 , is supplied to the soil surface in the hold. From the nozzle to the soil surface, the water moves in the form of directed high-pressure jets that do not interact with each other. 
Due to the automation of the water supply process, each of the sections of the complex pipeline 5 can be turned off.

This can be done through the operation of automatically controlled solenoid valves 3 .

In a complex circular pipe, continuous water withdrawal is used. It takes place at every point where a pressure jet flows during a water hammer.

In common case, the differential equation describing the pressure drop during continuous flow distribution in this hydraulic network has the form

$$
\frac{V d V}{g}+\frac{\left(V-V_{f l}\right)}{g} \frac{d Q}{Q}+d h_{l}=0
$$

where $d V$ - change in velocity inside a section with length $d l$, $\mathrm{m} / \mathrm{s} ; d Q$ - flow rate change inside a section with length $d l$, $\mathrm{m}^{3} / \mathrm{s} ; d h_{l}$ - pressure loss inside a section with length $d l, m_{\text {. }} ; V_{f l}$ - the velocity projection of the locally picked up flow onto the axis of the main flow of the entire stream, $\mathrm{m} / \mathrm{s}$.

In the case when inside the vessel's hydraulic system for soil destruction the partial flow rate for the creation of the shock jet is selected at an angle of $90^{\circ}$, the flow rate in the cross section of the pipeline, which is at a distance $x$ from its beginning, can be calculated as

$$
Q=Q_{t r}-Q_{p}\left(\frac{x}{l}\right)^{n}
$$

where $Q_{t r}$ - transit flow-rate equals to the flow-rate at the beginning of a complex pipeline, $\mathrm{m}^{3} / \mathrm{s} ; Q_{p}$ - path flow-rate, that is taken off along the entire length of the pipeline, $\mathrm{m}^{3} / \mathrm{s} ; n$ - exponent of path flow-rate change $n=0.5-1.5$ (when $n=1$ pick up of the flow is uniform and if $n>1$, - pick up of the flow increases along the main direction, when $n<1$ pick up of the flow decreases along the main direction of flow).

In the case when the partial pick up of the water flow to create shock jets inside the hold of the dredger is provided at an arbitrary angle to the main pipeline, the pressure change at the sampling point located at a distance $x$ from the beginning of the pipeline can be calculated as

$$
d h_{l}=f^{2}\left[\lambda \frac{l}{d}\left(\frac{x}{l}-\frac{x^{2}}{l^{2}}+\frac{x^{3}}{3 l^{3}}-\left(2-0.3 \frac{V}{V_{p f}}\right)\left(2 \frac{x}{l}-\frac{x^{2}}{l^{2}}\right)\right)\right] \frac{V_{p f}^{2}}{2 g}
$$

where $f$-relative distance between the nozzles; $\lambda$ - factor of hydraulic friction; $l$ - length of the pipeline, $m ; V_{p f}$ - velocity of the picked up partial flow, $\mathrm{m} / \mathrm{s}$.

The relative distance $f$ between the nozzles to create jets can be found as

$$
f=\frac{n \varepsilon S_{h}}{S_{p}}
$$

where $n$ - number of holes for the flow's pick up, $\varepsilon-$ compression ratio of the jet when it flows through the nozzle or the hole (for water, as a first approximation $\varepsilon$ can be taken as $\varepsilon=0.64$ ), $S_{h}$ and $S_{p}$ - cross-sectional area of the dispensing hole and pipeline, respectively, $\mathrm{m}^{2}$.

The number of holes $n$ for creating shock jets can be calculated as

$$
n=\frac{Q_{p}}{\mu S_{h} \sqrt{2 g\left(h_{a v}-H\right)}}
$$

where $\mu$ - hole discharge factor (for water, as a first approximation $\mu$ can be taken as $\mu=0.62$ ), $H$ - total water head at the beginning of the pipeline, $m$., $h_{a v}$ - average water head drop in the area between two distribution holes for soil destruction inside the vessel's hold, $m$.

The value of the average water head drop $h_{a v}$ can be calculated as

$$
h_{a v}=h_{1}+\frac{\Delta h}{2}-H
$$

where $h_{1}$ - piezometric water head at the beginning of the pipeline, $m$; $\Delta h$ - pressure loss in the area between two adjacent holes, $m ; H$ - water head in the substance surrounding the area of jet, $m$. The value of pressure (water head) along the length of a complex pipeline with a path distribution of fluid varies nonlinearly. Because of this reason, for each of the hole, the partial flow rate will not be the same. It should be calculated individually for each hole in which the shock jet is created. It must be done taking into account the value of water head in an exact cross-section of the pipe, i.e.

$$
q_{i}=\mu S_{h} \sqrt{2 g \Delta h_{i}}
$$

where $\Delta h_{i}=\left(h_{i}-H\right)$ is the difference between the water head in the considered pipeline hole and at the beginning of the pipeline, $m$. The developed technology of water hammer use is based on the force interaction between jets and the surface of compacted soil. When jets flow from the cone nozzles along the entire structure of the annular complex pipeline, a negative load will occur. The reason for its occurrence is the reactive force, which arises from the side of the moving flow to the cone nozzles. This reactive force can be found when one takes into account the pressure of the working fluid in the pipeline and the speed of its outflow from the cone nozzle. The general scheme of a single conical nozzle is shown in Figure 2-a. The diagram shows that it is a cylindrical pipe 2 connected on one side to the main pipe 1 , and on the other hand connected to a conical nozzle 3 .

When the flow passes by the cone nozzle, only tensile force will take place, and the overall force balance, in accordance with Fig. 2-b can be written as

$$
N_{d y n 2}=F_{1}+F_{2}+G+Q_{m} V_{1}-Q_{m} V_{2}
$$

where $N_{\text {dyn } 2}-$ the resultant between pressure and friction forces acting onto the flow of the working fluid along the surface of the walls of the pipeline and the cone nozzle, $N ; F_{1}$ и $F_{2}$ - pressure forces in the main pipeline and inside the cone nozzle, respectively, $N$; $Q_{m}$ - mass flow rate, $\mathrm{kg} / \mathrm{s} ; V_{1}$ and $V_{2}-$ velocity of the working fluid
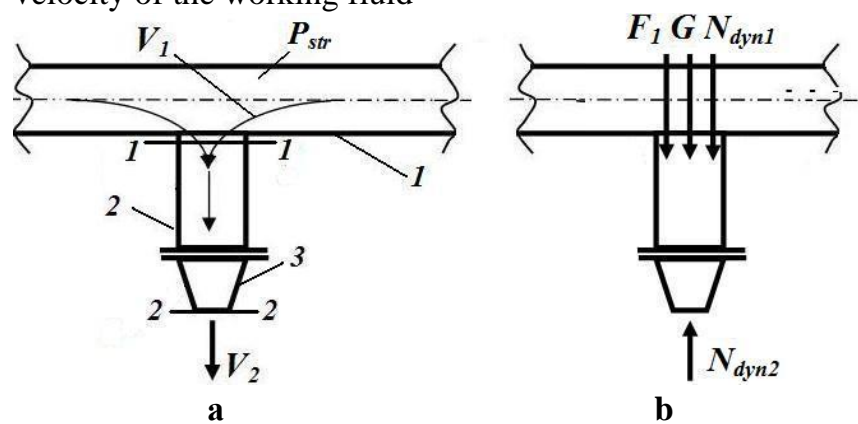

Fig. 2 Calculation scheme for determining reactive forces a - general scheme; b - power balance.

in the main pipeline and inside the cone nozzle, respectively, $\mathrm{m} / \mathrm{s}$.Finally, when flow passes the jet cone, reaction could be found as

$$
R=-N_{d y n 2}=\left(P_{s t r}-P_{a}\right) S_{1}+Q_{m} V_{2}-Q_{m} V_{1}
$$

where $P_{s t r}-$ shock wave pressure in the main pipeline, $P a$; $P_{a}$ - pressure at the cone nozzle outlet, equal to atmospheric pressure, $\mathrm{Pa}$; $\mathrm{S}_{1}$ - cross-sectional 


\section{Water Hummer Technology for Soil Destruction on Dredgers}

area of the distribution pipe, $m^{2}$.

In Figure 3 for a conical nozzle, the dependence between the reactive force and velocity of the flow in the main pipeline is shown. As one can see the pressure force of the jet of working fluid onto the layer of dense soil will be relatively high. Starting from velocity values in the main pipeline exceeding $5 \mathrm{~m} / \mathrm{s}$, the axial load on the soil surface is more then $100 \mathrm{~kg}$.

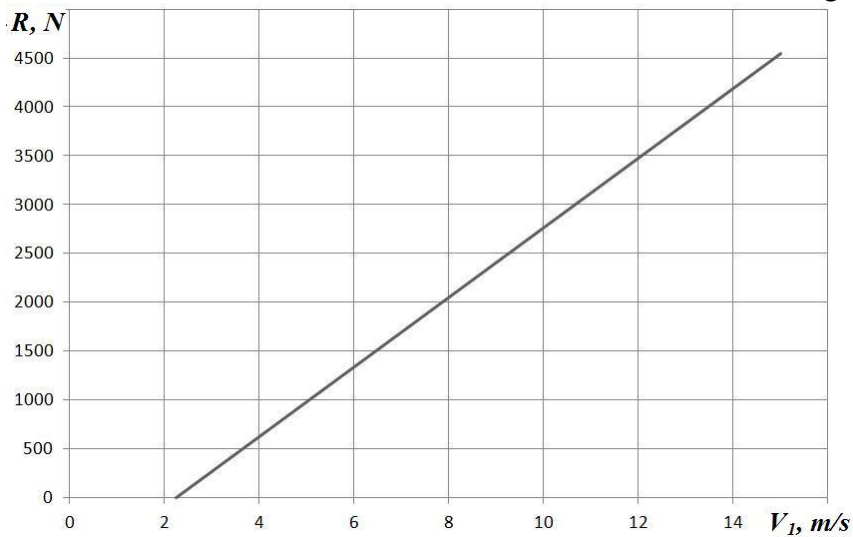

Fig. 3 Dependence between reactive force and inlet velocity of the flow

\section{RESULTS}

According to the problem statement one of the most important technological characteristics of the ship's soil erosion system is the dependence of the pressure, that is achieved during phases of the water hammer, on the time of the creation of the shock wave. In this case, the frequency of obtaining a shock jet on the soil surface will change the speed and quality of destruction of its surface compacted layer.

During experimental studies, this characteristic was investigated in detail. The fixation of pressure surges at fixed points in time was carried out using an explosion-proof digital manometer for liquids Crystal Engineering 5KPSIXP2I (USA). According to the manufacturer's passport data, its relative measurement error does not exceed $0.1 \%$. The sampling and recording frequency of the discrete signal by which the overpressure was determined was $0.5 \mathrm{sec}$.

In the graphs shown in Figure 4, Figure 5 and Figure 6 one can see the water hammer characteristics that were obtained during researches. They show that during the operation of the vessel's hydraulic system for destruction of the compacted soil layer in the hold of a vessel, it is possible to obtain from four to five phases of hydraulic water hummer, despite of the fact that during all experiments working parameters according to the value of the pressure received were limited by three phases only.

The main purpose to obtain the value of the shock pressure in the water jet is the greatest destruction of the soil. This dependence was found during experiments. The dependence in fig. 7 shows how the soil collapsed when interacting with shock jets during the first and second phases of water hammer. The result was obtained on two cone nozzles. The first cone nozzle was blocked by an electromagnetic valve after the first phase of the water hammer, and the second after the first two phases. The time of complete closure of the valves during operation was 0.001 seconds.

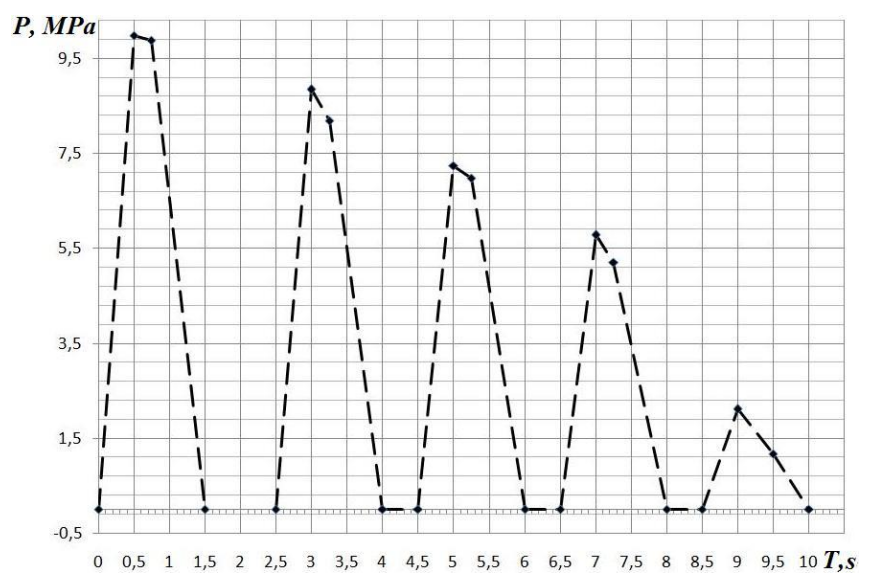

Fig. 4 Water hummer with five phases. Maximal pressure equals $9997000 \mathrm{~Pa}$

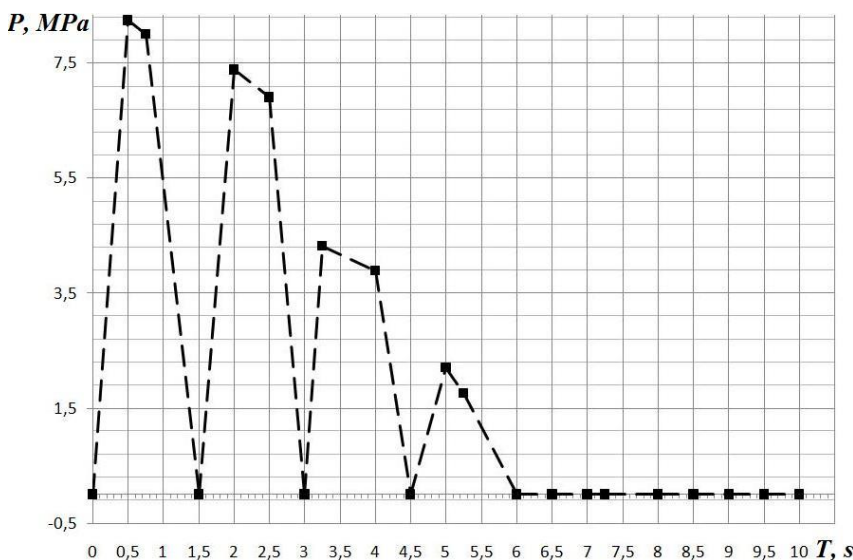

Fig. 5 Water hummer with four phases. Maximal pressure equals $8244000 \mathrm{~Pa}$

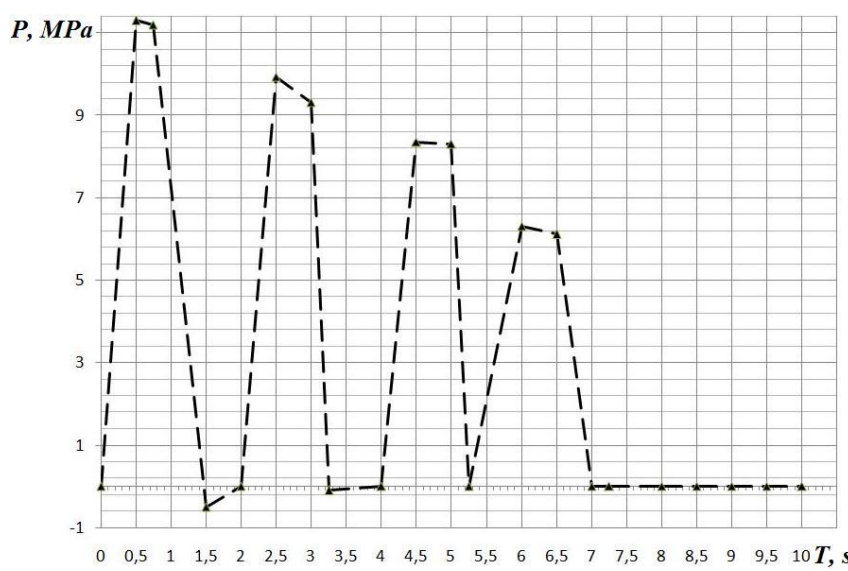

Fig. 6 Water hummer with four phases.Maximal pressure equals $11312000 \mathrm{~Pa}$

In fig. 7, the values of the magnitude of the developed shock pressure are plotted on the abscissa, and the depth $H$ of the resulting fosse in the ground is plotted on the ordinate. On the graph, the Roman numerals I, II and III indicate the results of three independent experiments, and the digital indicators 1, 2 and 3 correspond to the results of measurements in the first, second and third phases of the water hummer. All experimental data from fig. 7 presented in Table I. 


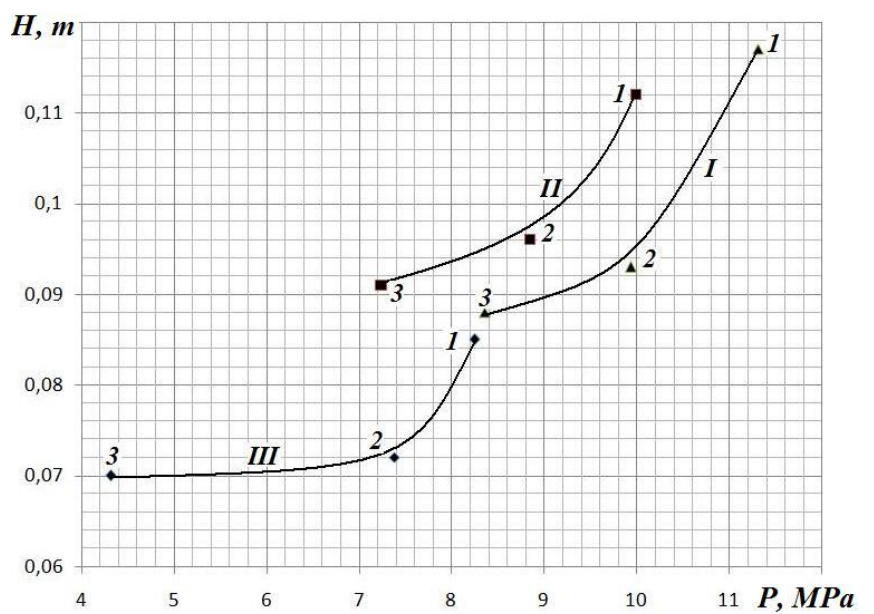

Fig. 7 Influence of shock pressure onto the depth of soil surface destruction

Table- I: Name Influence of shock pressure onto the depth of soil surface destruction

\begin{tabular}{|c|c|c|c|}
\hline \multirow{2}{*}{$\begin{array}{c}\text { Depth of } \\
\text { fosse, } \mathrm{m}\end{array}$} & \multicolumn{3}{|c|}{ Pressure strike during water hummer } \\
\cline { 2 - 4 } & I phase & II phase & III phase \\
\hline \multirow{3}{*}{$\mathrm{H}, \mathrm{m}$} & $11312000 \mathrm{~Pa}$ & $9942000 \mathrm{~Pa}$ & $8361000 \mathrm{~Pa}$ \\
\cline { 2 - 4 } & 0,117 & 0,093 & 0,088 \\
\hline \multirow{3}{*}{$\mathrm{H}, \mathrm{m}$} & $9997000 \mathrm{~Pa}$ & $8851000 \mathrm{~Pa}$ & $7246000 \mathrm{~Pa}$ \\
\cline { 2 - 4 } & 0,112 & 0,096 & 0,091 \\
\hline \multirow{3}{*}{$\mathrm{H}, \mathrm{m}$} & $8244000 \mathrm{~Pa}$ & $7383000 \mathrm{~Pa}$ & $4324000 \mathrm{~Pa}$ \\
\cline { 2 - 4 } & 0,085 & 0,072 & 0,07 \\
\hline
\end{tabular}

\section{DISCUSSION}

Main indicators of the process of soil destruction using a three-phase hydraulic shock are shown in Table 1. An analysis of each of the three experimental curves shown in Fig. 7 and numerical values in table. 1, gives an ability to make conclusion that the depth of soil destruction during its interaction with the shock water jet increases during the first two phases of the hydraulic shock only.

For the given series of three independent experiments, the change in the depth of destruction of the surface soil layer between the first and second phases was $24 \mathrm{~mm}, 16 \mathrm{~mm}$, and $13 \mathrm{~mm}$, respectively, and between the second and third, 5 $\mathrm{mm}, 5 \mathrm{~mm}$, and $2 \mathrm{~mm}$. In percentage terms, this change between the two phases (1-2 and 2-3) of hydraulic water hummer looks like this: $20.8 \%, 31.25 \%$ and 15 , 38\%.

The quality of the process of destruction of a dense soil layer using several phases of hydraulic water hummer will be greatly affected by the number of cone nozzle that are used in the closed-circuit pipeline. These units are used to create fosse in the soil through the interaction of high-pressure jets with the surface of the soil. The number of jets affects one of the most basic indicators of the workflow. This indicator is the final soil concentration in the slurry. In this case, the process of destruction of the surface layer of sand, which due to bad weather conditions (low temperature and high humidity) has become very dense, can be a good example.

The relationship between concentration of soil in the slurry and the number of water jets, that was used in the process is shown in Figure 8. As can be seen from the nomogram, this dependence is non-linear. It is possible to make a conclusion from this dependence that an increase in the number of cone nozzles (jets of shock pressure) leads to an increase in the concentration of sand in the slurry transported.

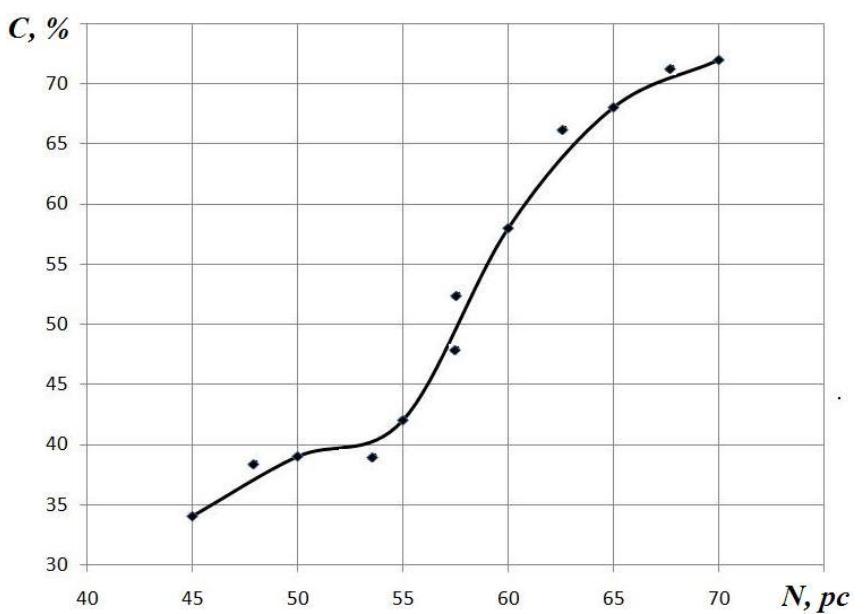

Fig. 8 Dependence between number of jets and concentration of sand in a slurry

From an economic point of view, a reasonable value of the working concentration of soil in the slurry is a value that is in the range from 40 to $70 \%$. The graph shows that the lower limit of this range of $40 \%$ was achieved when fifty-four cone nozzles were used. A further increase led to an abrupt increase in the volumetric content of soil in the slurry. The addition of six cone nozzles led to a change in the concentration value from 40 to $57 \%$.

Analysis of the obtained graphical dependence allows to make a conclusion that the rational number of shock jets (cone nozzles) is limited. After obtaining the maximum soil concentration in the slurry, which, for example, in Fig. 8 corresponds to the concentration of sand in the pulp equal to $68 \%$ when using 65 jets there is no need to use additional cone nozzles. An increase in their number from the point of view of transporting the flow of slurry does not make any sense. When the slurry moves in the pipeline, regardless of the degree of turbulization of the moving flow, almost complete sedimentation of the soil will occur and, as a result, the vessel operation will stop completely.

Due to the high inertia of the soil slurry, the process of soil taking away from the hold of a vessel does not imply an instant change in the operational characteristics of the process of loosening and subsequent transportation of the slurry. For high-quality operator's work when regulating the volume of soil discharged at the end of the soil pipeline and soil, taken from the surface of the vessel's hold, it is intended to use such indicators of the workflow that allow one to obtain the expected result in advance. In this case, the use of phase dynamic characteristics may be useful. An example of such characteristics is shown in Figure 9 and Figure 10. 


\section{Water Hummer Technology for Soil Destruction on Dredgers}

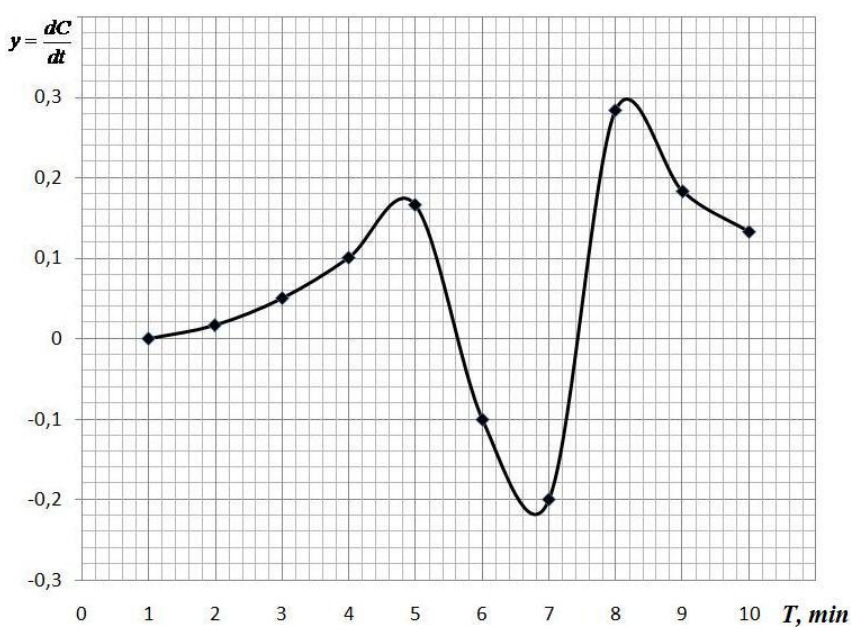

Fig. 9 Dynamic characteristic of soil concentration in a slurry

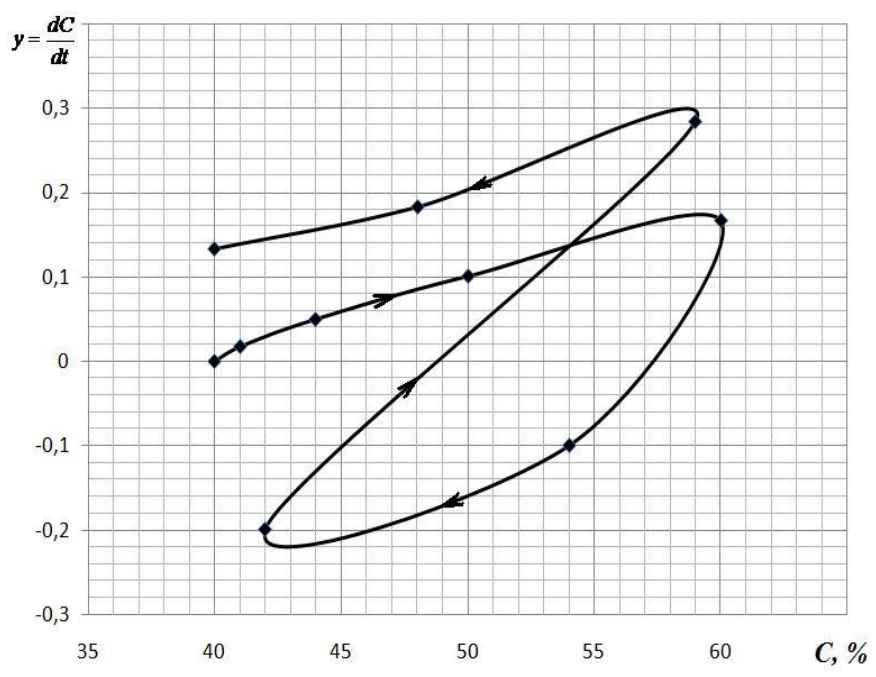

Fig. 10 Phase characteristic of soil concentration in a slurry

The plotting of dynamic characteristics should be carried out according to the following rules:

1. The dynamic characteristic can be a graded curve, which corresponds to a change in time of the flow gradient of the discharged slurry or the gradient of soil concentration in the resulting slurry.

2. The phase response curve is graduated over time with the abscissa $x$ (flow rate $Q$ or concentration $C$ ) and the ordinate $y=\frac{d x}{d t}$.

The difference in the application of two characteristics presented in Fig. 9 and Fig. 10 in the case of dredging fleet operation is in the technical support equipment of the vessel only. In the case when the soil concentration in the flow of transported slurry can be measured, it is necessary to use the dynamic characteristic which is shown in Fig. 9. In the case where the main measurement equipment is a flowmeter, then there should be used the phase characteristic, which is shown in Fig. 10.

In both graphs in Fig. 9 and Fig. 10 it is evident that the high-quality operation of the soil intake system in the hold of the vessel will be ensured only in one case. The values of ordinate $y$, which are plotted on the display of the operator of the dredger, should always be positive.

\section{CONCLUSION}

If the dense surface soil layer is destroyed, the necessary depth of the fosse obtained due to the interaction of the soil with the shock water jet can be obtained during the first two phases of the hydraulic water hummer. Further phases of water hammer are ineffective because they do not lead to an increase in the depth of surface's damage.

An increase in soil concentration in the slurry can be obtained by increasing a number of cone nozzles (jets of shock pressure). In this case, it must be considered that the increase in soil concentration in the transported slurry is limited by the process of sedimentation. An increase in a number of shock jets can lead to the fact that the concentration of soil in the slurry will cause the transportation process to stop. The working range of soil concentration in the slurry for its transportation should not exceed a value of $70 \%$.

Due to the high inertia of the flow of a slurry, the process of soil discharge from the hold of a vessel does not imply an instant change in the operational characteristics of the process of soil loosening and subsequent transportation of the slurry. The quality of the work of the operator of the dredger can be improved by using dynamic and phase characteristics that reflect the degree of change in the concentration of pulp in the transported flow.

\section{REFERENCES}

1. T. M. Tomas, Fundamentals of hydraulic dredging. ASCE Press. Reston. Virginia, 1996.

2. K.M. Lee, C. K. Shen, D. H. K. Leung, J. K. Mitchell, "Effects of Placement Method on Geotechnical Behavior of Hydraulic Fill Sands.' Journal of Geotechnical and Geoenvironmental Engineering, Vol. 125, No. 10, 1999, pp. 832-846.

3. R. Cornet, Wear in dredgers. The Dock and Harbor Authority, V. 56. 1975, pp.10-12.

4. Peter S. Bernard, Fluid Dynamics. New York: Cambridge University Press, 2015.

5. C. Pozrikidis, Fluid Dynamics: Theory, Computation, and Numerical Simulation, 3rd edition. New York: Springer, 2016.

6. John Sinclair, M.I. Min, Sand and Gravel. Quarrying Opencast and Alluvial Mining. Berlin Heidelberg, 2015.

7. I. Z. Maslov Dredger's slurry discharge process automatization. Electrotechnic and computer systems, Kiyv: “Technica”, № 10 (86), 2013, pp 80-85. Available: http://nbuv.gov.ua/UJRN/etks_2013_10_14

8. Michael H. de Freitas, "Withdrawal of Support by Surface Excavations", Engineering Geology, 2009, pp 247-294.

9. A. A. Ryder, S. C. Rapson, "Pipeline Technology (Book style with paper title and editor)", in Environmental Technology in the Oil Industry 2nd Edition. Oxoid Ltd, Hampshire, U.K., 2008, pp. 229-280.

10. D. Tsang, I. Lo, R. Surampalli, "Design, Implementation, and Economic/ Societal Considerations of Chelant-Enhanced Soil Washing". ASCE Library, 2012, pp. 1-26. Available: https://ascelibrary.org/doi/10.1061/9780784412183.ch01

\section{AUTHORS PROFILE}

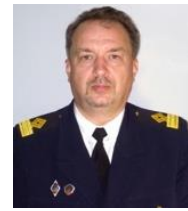

Igor Z. Maslov is currently working as an Associate Professor and Head of Ship`s Power Plants Operation and Systems Department of the Danube Institute of the National University "Odesa Maritime Academy", Izmail City, Ukraine. He earned his $\mathrm{PhD}$ degree from National University "Odesa Maritime Academy" (2016). His research interests include dredging technologies for different conditions of vessel operation, design and modernization of main dredger's technical systems, fluid mechanics of multiphase flows, complex analysis of dredging process for different vessels, IT technologies in dredging. ORCID: 0000-0003-1759-6077. E-mail: sartfm@yahoo.com. Mobile:+380673693946 


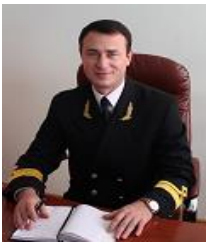

Valentin I. Chimshir is currently working as an Associate Professor and Director of the Danube Institute of the National University "Odesa Maritime Academy", Izmail City, Ukraine. He earned his $\mathrm{PhD}$ degree from Odessa National Maritime University (2009) and Doctor of Science degree from Odessa National Maritime University (2017). His research interests include project management on sea transport, development of new management methods for transport, new management methods development for shipbuilding. ORCID: 0000-0003-3621-2702, E-mail: chimshir@ukr.net. Mobile:+380965549377

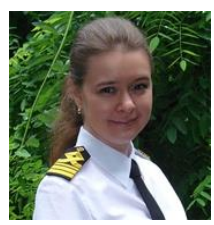

Varvara M. Piterska is currently working as Professor at the Department of Port Operations and Cargo Works Technology of the Odessa National Maritime University, Odessa Ukraine. She earned her $\mathrm{PhD}$ degree from Odessa National Maritime University (2011) and Doctor of Science degree from Odessa National Maritime University (2018). Her research interests include project management on sea transport, development of effective methods, models and mechanisms for risk-based management of innovative projects, portfolios and programs. ORCID: 0000-0001-5849-9033, E-mail: varuwa@ukr.net. Mobile +380675592377

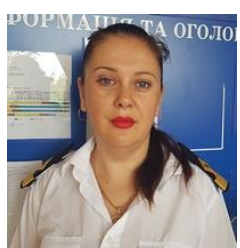

Anzhela I. Haidarzhy A Senior Lecturer of the Department of Navigation and Ship Management. A head of the Academic Services Department of the Danube Institute of the National University "Odesa Maritime Academy". Presently pursuing her $\mathrm{PhD}$ and her research interests include project management on sea transport, development of effective methods to monitor quality of technical operations on vessels, models and mechanisms of risk-based management, information technologies on sea transport, environmental problems of maritime transport, ORCID: 0000-0002-4072-1772, gaidarzhy.angela@gmail.com 